\title{
What Should the Systolic Blood Pressure Goal be in Adults with Hypertension?
}

\section{Wilbert S Aronow*}

Department of Medicine, Division of Cardiology, New York Medical College, Valhalla, NY, USA

The American Heart Association (AHA) 2007 guidelines recommend treating patients with hypertension at high risk for coronary events such as those with coronary artery disease, diabetes mellitus, chronic kidney disease, or a 10-year Framingham risk score of $10 \%$ or higher to have their systolic blood pressure reduced to less than $130 \mathrm{~mm} \mathrm{Hg}$ [1]. These guidelines also recommend that patients with hypertension and left ventricular systolic dysfunction have their systolic blood pressure reduced to less than $120 \mathrm{~mm} \mathrm{Hg}$ [1]. However, clinical trial data do not support these guidelines for treatment of patients with hypertension [2-17].

The American College of Cardiology Foundation (ACCF)/AHA 2011 expert consensus document on hypertension in the elderly developed in collaboration with the American Academy of Neurology, the American Geriatrics Society, the American Society for Preventive Cardiology, the American Society of Hypertension, the American Society of Nephrology, the Association of Black Cardiologists, and the European Society of Hypertension recommends that the systolic blood pressure be reduced to less than $140 \mathrm{~mm} \mathrm{Hg}$ in persons younger than 80 years and to 140 to $145 \mathrm{~mm} \mathrm{Hg}$ if tolerated in adults aged 80 years and older [18]. I strongly support these guidelines based on clinical trial data [2-17].

The American Diabetes Society 2013 guidelines recommend that diabetics with hypertension should have their systolic blood pressure reduced to less than $140 \mathrm{~mm} \mathrm{Hg}$ [19]. These guidelines also state that a systolic blood pressure less than $130 \mathrm{~mm} \mathrm{Hg}$ may be considered in younger patients with long life expectancy if achieved with few drugs and without side effects

The International Society of Nephrology 2012 guidelines for management of blood pressure in patients with non-dialysisdependent chronic kidney disease recommend that patients with chronic kidney disease without diabetes mellitus [20] or with diabetes mellitus [21] with hypertension and albuminuria less than $30 \mathrm{mg}$ per 24 hours should have their systolic blood pressure reduced to $\leq 140$ $\mathrm{mm} \mathrm{Hg}$. If albuminuria greater than $30 \mathrm{mg}$ per 24 hours is present, the systolic blood pressure may be reduced to $\leq 130 \mathrm{~mm} \mathrm{Hg}$ with a class II D indication which I would not recommend $[20,21]$.

The European Society of Hypertension/European Society of Cardiology 2013 guidelines for management of hypertension recommend lowering the systolic blood pressure to less than $140 \mathrm{~mm}$ $\mathrm{Hg}$ in patients at low to moderate cardiovascular risk, in patients with diabetes mellitus, in patients with a prior stroke or transient ischemic attack, in patients with coronary heart disease, and in patients with diabetic or non-diabetic chronic kidney disease [22]. In patients aged 65-79 years of age with a systolic blood pressure of $160 \mathrm{~mm} \mathrm{Hg}$ or higher, the systolic blood pressure should be reduced to between 140$150 \mathrm{~mm} \mathrm{Hg}$ with consideration of a systolic blood pressure less than $140 \mathrm{~mm} \mathrm{Hg}$ [22]. In patients older than 80 years with a systolic blood pressure of $160 \mathrm{~mm} \mathrm{Hg}$ or higher, the systolic blood pressure should be reduced to between $140-150 \mathrm{~mm} \mathrm{Hg}$ provided they are in good physical and mental conditions [22].

The 2013 Eighth Joint National Committee (JNC 8) guidelines for management of hypertension recommend lowering the systolic blood pressure to less than $140 \mathrm{~mm} \mathrm{Hg}$ in patients younger than 60 years and in patients with diabetes mellitus or chronic kidney disease [23]. These guidelines recommend lowering the systolic blood pressure in patients aged 60 years or older to less than $150 \mathrm{~mm} \mathrm{Hg}$ if they do not have diabetes mellitus or chronic kidney disease [23]. The minority view from JNC 8 summarizes the evidence that the systolic blood pressure goal in patients younger than 80 years with hypertension without diabetes mellitus or chronic kidney disease should be less than $140 \mathrm{~mm}$ $\mathrm{Hg}$ [24]. I concur with this view.

Among 8,354 patients aged 60 years and older with coronary artery disease in the International Verapamil SR-Trandolapril Study (INVEST), a baseline systolic blood pressure of $150 \mathrm{~mm} \mathrm{Hg}$ or higher, and 22,308 patient years of follow-up, $57 \%$ had a systolic blood pressure less than $140 \mathrm{~mm} \mathrm{Hg}, 21 \%$ had a systolic blood pressure of 140 to 149 $\mathrm{mm} \mathrm{Hg}$, and $22 \%$ had a systolic blood pressure of $150 \mathrm{~mm} \mathrm{Hg}$ or higher [25]. The primary outcome of all-cause mortality, nonfatal myocardial infarction, or nonfatal stroke occurred in $9.36 \%$ of patients with a systolic blood pressure less than $140 \mathrm{~mm} \mathrm{Hg}$, in $12.71 \%$ of patients with a systolic blood pressure of $140-149 \mathrm{~mm} \mathrm{Hg}$, and in $21.3 \%$ of patients with a systolic blood pressure of $150 \mathrm{~mm} \mathrm{Hg}$ or higher $(\mathrm{p}<0.0001)$ [25]. Using propensity score analyses, compared with a systolic blood pressure less than $140 \mathrm{~mm} \mathrm{Hg}$, a systolic blood pressure of 140 to 149 $\mathrm{mm} \mathrm{Hg}$ increased cardiovascular mortality $34 \%(\mathrm{p}=0.04)$, total stroke $89 \%(\mathrm{p}=0.002)$, and nonfatal stroke $70 \%(\mathrm{p}=0.03)$ [25]. Compared with a systolic blood pressure of less than $140 \mathrm{~mm} \mathrm{Hg}$, a systolic blood pressure of $150 \mathrm{~mm} \mathrm{Hg}$ or higher increased the primary outcome $82 \%(\mathrm{p}<0.0001)$, all-cause mortality $60 \%(\mathrm{p}<0.0001)$, cardiovascular mortality $218 \%(\mathrm{p}<0.0001)$, and total stroke $283 \%(\mathrm{p}<0.0001)$ [25].

Elderly persons are currently being undertreated for hypertension $[18,26]$. If the JNC 8 panel recommendations are implemented, 6 million USA adults aged 60 years and older would not be eligible for antihypertensive drug therapy, and treatment intensity would be decreased for an additional 13.5 million older persons [27], leading to increased incidences of coronary events, stroke, heart failure, cardiovascular mortality, and other adverse events associated with poor control of hypertension. The JNC 8 guidelines raising the threshold for initiating antihypertensive drug treatment and systolic blood pressure goal for older persons places high-risk women, especially AfricanAmerican, at unnecessary excess risk for cardiovascular morbidity and mortality [28].

${ }^{*}$ Corresponding author: Wilbert S. Aronow, Professor of Medicine, Cardiology Division, New York Medical College, Macy Pavilion, Room 138, Valhalla, NY 10595 USA, Tel: (914) 493-5311; Fax: (914) 235-6274; E-mail: wsaronow@aol.com

Received November 05, 2014; Accepted November 20, 2014; Published November 25, 2014

Citation: Aronow WS (2014) What Should the Systolic Blood Pressure Goal be in Adults with Hypertension?. J Hypertens 3: 189. doi:10.4172/2167-1095.1000189

Copyright: (c) 2014 Aronow WS. This is an open-access article distributed under the terms of the Creative Commons Attribution License, which permits unrestricted use, distribution, and reproduction in any medium, provided the original author and source are credited. 
The 2014 American Society of Hypertension (ASH)/ International Society of Hypertension (ISH) guidelines recommend lowering the systolic blood pressure to less than $140 \mathrm{~mm} \mathrm{Hg}$ in adults younger than 80 years [29]. In adults aged 80 years and older, these guidelines recommend lowering the systolic blood pressure to less than $150 \mathrm{~mm}$ $\mathrm{Hg}$ unless these patients have diabetes mellitus or chronic kidney disease when a goal of less than $140 \mathrm{~mm} \mathrm{Hg}$ can be considered [29].

I would recommend starting antihypertensive drug treatment in patients younger than 80 years when the systolic blood pressure is higher than $140 \mathrm{~mm} \mathrm{Hg}$ or the diastolic blood pressure is higher than $90 \mathrm{~mm} \mathrm{Hg}$. In patient's aged 80 years and older without diabetes mellitus or chronic kidney disease, I would recommend starting antihypertensive drug when the systolic blood pressure is higher than $150 \mathrm{~mm} \mathrm{Hg}$ or the diastolic blood pressure is higher than $90 \mathrm{~mm} \mathrm{Hg}$. If these patients have diabetes mellitus or chronic kidney disease, I would consider starting antihypertensive drug treatment when the systolic blood pressure is higher than $140 \mathrm{~mm} \mathrm{Hg}$.

\section{References}

1. Rosendorff C, Black HR, Cannon CP, Gersh BJ, Gore J, et al (2007) Treatment of hypertension in the prevention and management of ischemic heart disease: a scientific statement from the American Heart Association Council for High Blood Pressure Research and the Councils on Clinical Cardiology and Epidemiology and Prevention. Circulation 115: 2761-2788.

2. [No authors listed] (1991) Prevention of stroke by antihypertensive drug treatment in older persons with isolated systolic hypertension. Final results of the Systolic Hypertension in the Elderly Program (SHEP). SHEP Cooperative Research Group. JAMA 265: 3255-3264.

3. Perry HM Jr, Davis BR, Price TR, Applegate WB, Fields WS, et al. (2000) Effect of treating isolated systolic hypertension on the risk of developing various types and subtypes of stroke: the Systolic Hypertension in the Elderly Program (SHEP). JAMA 284: 465-471.

4. Kostis JB, Davis BR, Cutler J, Grimm RH Jr, Berge KG, et al. (1997) Prevention of heart failure by antihypertensive drug treatment in older persons with isolated systolic hypertension. SHEP Cooperative Research Group. JAMA 278: 212-216.

5. Beckett NS, Peters R, Fletcher AE, Staessen JA, Liu L, et al. (2008) Treatment of hypertension in patients 80 years of age or older. N Engl J Med 358: 1887-1898.

6. Bangalore S, Qin J, Sloan S, Murphy SA, Cannon CP; PROVE IT-TIMI 22 Tria Investigators (2010) What is the optimal blood pressure in patients after acute coronary syndromes?: Relationship of blood pressure and cardiovascula events in the PRavastatin OR atorVastatin Evaluation and Infection TherapyThrombolysis In Myocardial Infarction (PROVE IT-TIMI) 22 trial. Circulation 122: 2142-2151.

7. Cooper-DeHoff RM, Gong Y, Handberg EM, Bavry AA, Denardo SJ, et al (2010) Tight blood pressure control and cardiovascular outcomes among hypertensive patients with diabetes and coronary artery disease. JAMA 304: 61-68.

8. ACCORD Study Group, Cushman WC, Evans GW, Byington RP, Goff DC Jr, et al. (2010) Effects of intensive blood-pressure control in type 2 diabetes mellitus. N Engl J Med 362: 1575-1585.

9. Mancia G, Schumacher H, Redon J, Verdecchia P, Schmieder R, et al. (2011) Blood pressure targets recommended by guidelines and incidence of cardiovascular and renal events in the Ongoing Telmisartan Alone and in Combination With Ramipril Global Endpoint Trial (ONTARGET). Circulation 124: $1727-1736$

10. Upadhyay A, Earley A, Haynes SM, Uhlig K (2011) Systematic review: blood pressure target in chronic kidney disease and proteinuria as an effect modifier. Ann Intern Med 154: 541-548.

11. Appel LJ, Wright JT Jr, Greene T, Agodoa LY, Astor BC, et al. (2010) Intensive blood-pressure control in hypertensive chronic kidney disease. N Engl J Med 363: 918-929.

12. Lazarus JM, Bourgoignie JJ, Buckalew VM, Greene T, Levey AS, et al. (1997) Achievement and safety of a low blood pressure goal in chronic renal disease. The Modification of Diet in Renal Disease Study Group. Hypertension 29: 641-650.
13. Ruggenenti P, Perna A, Loriga G, Ganeva M, Ene-lordache B, et al. (2005) Blood-pressure control for renoprotection in patients with non-diabetic chronic renal disease (REIN-2): multicentre, randomised controlled trial. Lancet 365 939-946.

14. Banach M, Bhatia V, Feller MA, Mujib M, Desai RV, et al. (2011) Relation of baseline systolic blood pressure and long-term outcomes in ambulatory patients with chronic mild to moderate heart failure. Am J Cardiol 107: 1208-1214.

15. Ovbiagele B, Diener HC, Yusuf S, Martin RH, Cotton D, et al. (2011) Level of systolic blood pressure within the normal range and risk of recurrent stroke. JAMA 306: 2137-2144.

16. SPS3 Study Group, Benavente OR, Coffey CS, Conwit R, Hart RG, et al. (2013) Blood-pressure targets in patients with recent lacunar stroke: the SPS3 randomised trial. Lancet 382: 507-515.

17. Banach M, Bromfield S, Howard G, Howard VJ, Zanchetti A, et al. (2014) Association of systolic blood pressure levels with cardiovascular events and all-cause mortality among older adults taking antihypertensive medication. Int J Cardiol 176: 219-226.

18. Aronow WS, Fleg JL, Pepine CJ, Artinian NT, Bakris G, et al. (2011) ACCF/ AHA 2011 expert consensus document on hypertension in the elderly: a report of the American College of Cardiology Foundation Task Force on Clinical Expert Consensus Documents. Developed in collaboration with the American Academy of Neurology, American Geriatrics Society, American Society for Preventive Cardiology, American Society of Hypertension, American Society of Nephrology, Association of Black Cardiologists, and European Society of Hypertension. J Am Coll Cardiol 57: 2037-2114.

19. American Diabetes Association (2013) Standards of Medical Care in Diabetes-2013. Diabetes Care 36: S11-S66

20. [No authors listed] (2012) Chapter 3: Blood pressure management in CKD ND patients without diabetes mellitus. Kidney Int Suppl (2011) 2: 357-362.

21. [No authors listed] (2012) Chapter 4: Blood pressure management in CKD ND patients with diabetes mellitus. Kidney Int Suppl (2011) 2: 363-369.

22. Mancia G, Fagard R, Narkiewicz K, Redon J, Zanchetti A, et al. (2013) 2013 $\mathrm{ESH} / \mathrm{ESC}$ guidelines for the management of arterial hypertension: The Task Force for the Management of Arterial Hypertension of the European Society of Hypertension (ESH) and of the European Society of Cardiology (ESC). Eur Heart J 34: 2159-2219.

23. James PA, Oparil S, Carter BL, Cushman WC, Dennison-Himmelfarb C, et al. (2014) 2014 evidence-based guideline for the management of high blood pressure in adults. Report From the Panel Members Appointed to the Eighth Joint National Committee (JNC 8). JAMA 311: 507-520.

24. Wright JT Jr, Fine LJ, Lackland DT, Ogedegbe G, Dennison Himmelfarb CR (2014) Evidence supporting a systolic blood pressure goal of less than 150 $\mathrm{mm} \mathrm{Hg}$ in patients aged 60 years or older: the minority view. Ann Intern Med 160: 499-503.

25. Bangalore S, Gong Y, Cooper-DeHoff RM, Pepine CJ, Messerli FH (2014) 2014 Eighth Joint National Committee panel recommendation for blood pressure targets revisited: results from the INVEST study. J Am Coll Cardiol 64: 784-793.

26. Lloyd-Jones DM, Evans JC, Levy D (2005) Hypertension in adults across the age spectrum: current outcomes and control in the community. JAMA 294: 466-472.

27. Navar-Boggan AM, Pencina MJ, Williams K, Sniderman AD, Peterson ED (2014) Proportion of US adults potentially affected by the 2014 hypertension guideline. JAMA 311: 1424-1429.

28. Krakoff LR, Gillespie RL, Ferdinand KC, Fergus IV, Akinboboye O, et al. (2014) 2014 hypertension recommendations from the eighth joint national committee panel members raise concerns for elderly black and female populations. J Am Coll Cardiol 64: 394-402.

29. Weber MA, Schiffrin EL, White WB, Mann S, Lindholm LH, et al. (2014) Clinical practice guidelines for the management of hypertension in the community. A statement by the American Society of Hypertension and the International Society of Hypertension. J Hypertens 32: 3-15. 